\title{
THE EXPERT WITNESS AND MEDIATION
}

\section{E. LYLE GROSS}

This article examines many aspects of the role of the expert witness in dispute resolution, particularly in mediation. The author suggests that expert witmesses will function more effectively in a mediation than in an adversarial setting, due to the nature of their scientific training: objectivity; an inquisitorial approach, and the wide-spread sharing of knowledge. The author supports this conclusion with an historical review of the expert witness in dispute resolution. Next is a discussion of the expert in mediation. The role of the expert in mediation is of paramount importance; in some circumstances the expert may even function as the mediator as well. The author concludes with a guide to preparing the expert witness in dispute resolution.
Le présent article examine de nombreux aspects du rôle de témoin expert dans le règlement des différends, surtout en médiation. L'auteur suggère que les témoins experts fonctionnent plus efficacement dans une médiation que dans un système accusatoire. Ceci s'explique par leur formation scientifique, caractérisée parl'objectivité. une approche inquisitoire et le partage largement répandue du savoir. L'auteur soutient sa conclusion en procédant à un examen historique du témoin expert dans le règlement des différends. Il étudie ensuite le rôle de l'expert en médiation, lequel revêt une importance capitale. Dans certains cas, il arrive mème que l'expert serve également de médiateur. L'auteur conclut en offrant un guide destiné à préparer le témoin expert au règlement des différends.

\section{TABLE OF CONTENTS}

I. INTRODUCTION $\ldots \ldots \ldots \ldots \ldots \ldots \ldots \ldots \ldots \ldots \ldots$

II. THE EXPERT AND TRIAL $\ldots \ldots \ldots \ldots \ldots \ldots \ldots \ldots \ldots 71$

III. HISTORICAL REVIEW $\ldots \ldots \ldots \ldots \ldots \ldots \ldots \ldots \ldots \ldots$

IV. THE EXPERT AND MEDIATION $\ldots \ldots \ldots \ldots \ldots \ldots \ldots 78$

V. PREPARING THE EXPERT $\ldots \ldots \ldots \ldots \ldots \ldots \ldots \ldots \ldots 83$

\section{INTRODUCTION}

The purpose of this article is to examine the role of the expert witness in mediation. Mediation provides one of the few forums designed to resolve disputes, and to be conducted well, full disclosure and information exchange is paramount. The adversarial environment, however, throws all who participate into one corner or another where the prime objective is to win. The expert witness in this situation (decision by trial) may be called upon to strengthen a position. The more experienced, more qualified and more credible the expert is, the more in demand he or she may be in the adversarial environment. An expert who "performs" well in court becomes a valuable commodity and unfortunately this popularity may have little to do with the depth of knowledge or wisdom the expert may have.

A recent case illustrates where an expert's opinion can successfully be negated by another expert from the opposing side who, in this situation, practices in a completely different field. The case involved fibromyalgia, a reasonably well documented clinical

B.Sc. (Hons.), M.Sc., M.D., F.R.C.P. (C); Adjunct Professor, University of Alberta. 
condition that afflicts many patients in today's society. Without defending the existence of this medical entity, specialists from many fields of study were called upon to serve as expert witnesses to the courts in a case involving fibromyalgia. The case is well known to all who practice personal injury law in Alberta. In Mackie v. Wolfe, the judge discounted evidence by the rheumatologist and preferred the evidence of a psychiatrist in concluding that fibromyalgia was a questionable entity.' It is submitted that one of the reasons for discounting the rheumatologist's evidence was because of his "personal, and perhaps financial interest in perpetuating the existence of this condition."2 The power of the expert witness is illustrated in this case where Madam Justice B.L. Rawlins understandably relied heavily on expert evidence in arising at her decision.

The repercussions of this decision were far reaching in the Alberta community: insurance companies capitalized on the decision, terminating benefits for many who suffered from fibromyalgia; and some defence counsellors positioned their cases on a "crumbling skull" rather than a "thin skull" theory. Whether fibromyalgia, chronic fatigue syndrome, repetitive strain injury or psychosomatic illness exists is not the issue. What is concerning is the suggestion that an expert's opinion is swayed by monetary reward and that clinical conditions can be fabricated to "create" business. We could ask ourselves: if this is so, what came first, the pain patient or the pain clinic? Few patients would hesitate to answer. It also causes concern that one specialist (a psychiatrist) so completely negated another expert's (a rheumatologist's) opinion, as the field of study was so different.

The reason this article starts out by discussing the expert's role in the adversarial environment is to illustrate just how some of today's experts have become influenced by many factors. The reputation of the expert witness today has in some ways become tarnished. To better appreciate the potential of the expert witness, as we see in mediation, a discussion of the expert's performance in the courtroom helps us critically examine today's expert. A brief review of the historical evolution of the expert witness also helps put into perspective the fact that expert opinion is based on much more than that which we see on an x-ray or in a laboratory test. The mediation environment may eventually prove to be the only pure forum where experts can function without compromise and can return to their original intended role. In effect, experts are given the opportunity to return to their roots as educators to the court. Today's experts, at least those who choose to serve the courts, must be increasingly cognizant of their true intended purpose. The expert is, however, ignorant of legal process and has little understanding of Rules of Court, and while the expert will serve the court as best as he or she can, lawyers should spend a great deal of time preparing the expert and should educate them on key principles.

Hopefully what follows is conceptually general enough to apply to expert witnesses from most fields of study. While my bias is that of the medical expert, this slant can still serve to illustrate just how some experts can be pushed to the limits of ethical compromise in any field. Medicine (as with many other sciences) is an art based on 
scientific principles, and the adversarial "world" sometimes demands answers to questions that cannot be answered. Some fields of study, although, may be more conducive to the white and black milieu of decision by trial.

Experts often follow beliefs and theories which in some circumstances cannot be proven and must be discussed amongst colleagues. Information sharing is paramount. Mediation encourages information exchange in the search for a reasonable compromise or explanation for that which we see. International disputes may best be resolved through mediation: for example, expert evidence on fishing stocks may reveal concrete figures, but the impact on the less tangible topic of a nation's "right" to those stocks becomes grey and uncertain. Environmental disputants may argue the rights of "all" to preserve a forest, while financial experts may present black and white evidence about the need for clear-cutting. These issues are very difficult to resolve without free discussion and exchange of data, ideas and compromise solutions.

The greater the degree of grey (where issues are involved), the greater the need to exchange ideas, concepts and information. Mediation sets the optimum stage for fact finding and information sharing, and the "ideal setting" for some experts to maximize their contribution is in the mediation forum.

The adversarial environment may benefit from re-examining its own dependence on the expert through recognizing how the expert performs in mediation. Positive features seen in mediation may in part be extracted and utilized in the courtroom without compromising the principles behind resolution by trial.

Rigid adherence to any perspective must be viewed cautiously, and when significant grey surrounds an issue, experts who present themselves in this way should be challenged. Experts can improve their image, but to do so they must examine themselves and adopt a perspective which is ethical and is consistent with their training as scientists.

All professional expert witnesses should be given the opportunity to serve in the mediation forum, as they may then appreciate how they often have become tools in the adversarial environment: initially relied upon and then slowly moved aside by defence or plaintiff counsel when their popularity diminishes.

\section{THE EXPERT AND TRIAL}

As mentioned earlier, dispute resolution may take different formats. The format chosen is dependent upon many factors and is often beyond the control of the "victim" or "victims." A high profile dispute may require an open forum of public display. A controversial issue, where public impression is important, may result in mediation being the best venue of dispute resolution. In other circumstances, an individual, corporation or government party may adopt a position which cannot be compromised and therefore mediation may not be an option for resolving the dispute. Some issues are more conducive to resolution by mediation than others and there are many factors which determine this. The success, experience and skill set of the expert witness chosen may 
also impact on whether a dispute is best settled by mediation or trial. Choosing the method of dispute resolution will depend on many other factors: the nature and profile of the issue; the amount of money involved; and the overall impact of issue in question.

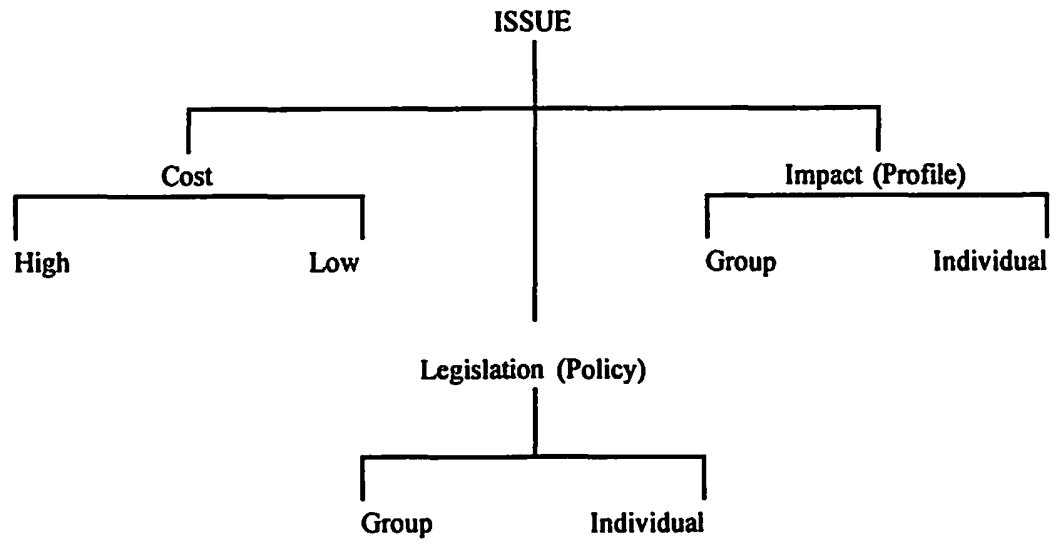

When the chosen forum for dispute resolution is the courtroom setting, the objective of representative counsel is to win; and in order to successfully present a position to judge or jury, lawyers will draw upon the many tools available to them. These tools may include various sections of the law, witnesses, a well researched case and a strong expert witness, or they may rely on their own oratory skills. In North America, case law serves as the basis for most decisions and when building the case, the lawyer will sometimes become reliant on their expert witness to such an extent that their opinion becomes the base of their pyramid of approach.

The expert witness may not only strengthen a position, but in some cases as stated, the expert opinion could become the very foundation of a position. Thus, the seed is planted whereby tremendous pressure is put on the expert to perform well. The role of the expert witness will, of course, vary from jurisdiction to jurisdiction, from field of study to field of study and from case to case. Choosing the right expert can prove difficult and, as many will attest to, the right or wrong expert could win or lose a case respectively.

Reynolds $^{3}$ defines the expert as a person having special skills or knowledge. The expert witness has six important functions requiring differing skills to execute:

- To present his evidence by answering the questions addressed to him. The questions are likely to be based on his own report and come from examination in chief, cross examination, or questions posed from the bench.

- To listen to the evidence presented.

- To participate in negotiations for settlement (where possible). 
In addition to these the expert should:

- $\quad$ Serve to educate the courts.

- Remain objective.

- $\quad$ Not become an advocate. ${ }^{4}$

A partisan position is unacceptable to the court and sooner or later the biased expert witness gains a reputation as such. Experts are nonetheless human and they can unknowingly become trapped in an advocacy role. With good initial intentions, the expert in fact could become a more vocal advocate than the lawyer, and should this occur, credibility inevitably becomes an issue.

Experts caught in an advocacy role clearly abrogate their responsibility. They do not serve the court well, nor do they serve the client well. Their "life span" can be short and if their written opinions become biased documents, it can be interpreted as selfserving. The decision in Mackie v. Wolfe may indeed reflect the general attitude concerning some experts or it may simply reflect the opinion of that judge dealing with that case on that day. Experts can choose to become so narrow in their focus that they may add very little to case resolution. For instance, an orthopaedic surgeon is not just an orthopaedic surgeon. Specialists are also generalists as well; to ignore the whole is to ignore the very roots of their education. While the expert is qualified in a certain area of expertise, the context of the opinion must be kept in mind. This narrow focus, while valid, can have detrimental and destructive repercussions. The following example serves to illustrate the point:

A 55-year-old labourer suffers a fracture to the right leg. The fracture invades the joint resulting in what is described as mild post traumatic arthritis to the knee. Infection sets in and the limb requires additional medical/surgical treatment. Two and one half years after the accident, the surgeon declares the patient fit to return to work and states to the third party that he finds no medical reason to account for ongoing disability. The surgeon, although not an expert in psychiatry, failed to inquire what the patient felt about going to work and the patient was eventually (retrospectively) found to be taking high doses of antidepressant medications. The family was being ripped apart by the psychosocial impact the injury had on them as a whole and at one time the patient was even suicidal. The orthopaedic surgeon was the only clinician reporting to the third party insurer and maintained that there was no reason that the patient could not return to work. No one identified the true cause of disability. Although the obligation as an orthopaedic was complete, as a generalist he did not bother to consider that there might be other factors (outside his area of speciality) that might be contributing to his patient's disability (recommending specialist involvement). Appropriate referrals could and should have been recommended.

Unfortunately, the adversarial nature of most methods of dispute resolution encourages advocacy and inflexibility of opinion. Abuse or simple misuse of terminology on the part of the expert can also impede the resolution process. A 
rheumatologist's examination stating that there are no findings to account for pain represents the rheumatologist's perspective only. Similarly, an environmentalist who states that she is an expert "only" on the effects of sulphur dioxide on plant synthesis ignores that generalizations can be made. The ability to generalize is a basic principle behind all science. A biologist is trained as a generalist first, then specializes and subspecializes in an area of narrow focus and expertise. Expressing an opinion with tunnel vision can serve to confuse and deflect from the broader picture. This is a powerful tactic. Opinions taken in context may reveal that there is little true difference of expert opinions and the problems this approach causes are apparent in court.

Experts of course must clearly and succinctly express their opinion on the well defined area that they have been qualified in. Experts might walk a thin line of ethics where the impression is given that this narrow opinion is the only perspective. The Rules of Court will restrict an expert's opinion to their qualified area, and therefore the opposing lawyer -should have the resources to address the context of the opinion expressed. The issue must be clear so that the context can be appreciated. The expert who fails to consider significant pathology, irrespective of whether it lays in their field of studies or not, may be discharging some of their responsibility.

"Probable or possible," "narrow or broad," "definitive or reasonable," are questions that experts are also called upon to answer (evidentiary facts). Experts should be encouraged to draw reasonable conclusions. When the expert makes a statement that is too polarized, particularly when the issues are controversial, this should evoke skepticism. An expert who shows little flexibility may be expressing a distorted opinion and equal caution should prevail.

The adversarial dispute resolution model, however, is of course not representative of the true manner with which experts function in the real world. In the "real world," open communication and exchange of information amongst the experts is demanded; this approach, however, detracts from the adversarial win/lose philosophy. It does not serve respective counsel to encourage "their" expert to share information. Experts have been heard to say, "Why should I enlighten my colleague when he has drawn incorrect conclusions?" This in reality could result in the death of a patient, or equally the death of a forest. Judge and jury are forced to formulate their decisions based on limited facts which are skewed by the expert's opinion and whose narrow focus appears to represent the whole. In complicated cases, many experts may be called upon with many facts presented. Piecing together all this information can become an insurmountable challenge for the courts. One expert's opinion is chosen over another's, white is chosen over black. However, to seek the truth, opinions should be put into context. Clearly identifying a witness' field of expertise helps at the outset and puts into perspective what the expert is contributing. When experts from the same field are pitted head to head, however, the attempt to uncover the truth becomes increasingly difficult in an adversarial setting where information sharing is discouraged.

The broad question in any field, however, should not be glossed over when facts are presented. Opinions based on a very narrow perspective and presented as though they are all-encompassing are skewed and by definition biased. This bias is a prejudiced 
opinion and is forced by the very nature of the adversarial system. The expert witness is no more than a purchased opinion skilfully tailored to be skilfully manoeurred by ipsilateral counsel.

An expert whose only redeeming features are that he presents well and sounds convincing in court cannot survive in the courtroom for long. This expert will not survive the litmus test demanded by colleagues in the community; in turn he will unlikely be acceptable to the courts. Flexibility, exchange of information and discussion are the tools of survival for any expert. We merely "tolerate" experts who position themselves (rigid and inflexible) as the definitive authority on a topic. An expert gifted with oratory skills, compassion, a thirst for knowledge and with the characteristic of thoroughness (that colleagues demand) should survive in court and in the community equally well.

\section{Lord McMillan stated:}

I am not certain that any scientific man ought to become partisan to one side. He may be the partisan of an opinion but ought never accept a retainer to advocate a particular view merely because it is the view which is in the interests of the party who has retained him. To do so is to prostitute science and practice a fraud on the administration of justice. The true rock of the expert witness is to offer counsel the best assistance he can by getting at the truth. It is in some form of consultative capacity that the abilities of professional men are best utilized in the public service. ${ }^{5}$

The make-up of today's expert, however, has opened the door of scrutiny. Although it was once thought that an expert could not be sued for their third party opinion, recent case law challenges this. ${ }^{6}$

In Canada, prior to 1991 there were few cases of third party negligence in which an expert, whose opinion resulted in a negative outcome, became liable for his or her opinion. Professor Gerald Robertson points out that in the United States there are cited cases where experts became accountable for the ramifications of their opinion. Professor Robertson summarizes one such case, North American Co. for Life \& Health Insurance v. Berger ${ }^{7}$ as follows:

[A] psychiatrist retained by the Federal Aviation Administration assessed a number of air traffic controllers as being totally disabled for work. Many of these employees held disability insurance policies, and the insurer (relying on the psychiatrist's assessment) paid out their claims. Later it was discovered that the psychiatrist's assessment was incorrect and the insurer sued the psychiatrist for negligence. The court held that this claim stated a valid cause of action. ${ }^{8}$

S See supra note 3.

6 See G. Robertson, "Medical Assessment and Professional Liability" in L.E. Gross, ed., Injury Evaluation: Medicolegal Principles (Toronto: Butterworths, 1991) 23.

7648 F. 2d 305 (5th Cir., 1981); cert. denied 454 U.S. 1084 (1981).

Robertson, supra note 6 at 29. 


\section{Professor Robertson describes another similar situation in an earlier case: ${ }^{9}$}

[I]n Wharton Transport Corp. v. Bridges, an employer retained a physician to examine one of its employees to determine whether he was fit to return to work as a truck driver. The physician stated that the employee was fit. Subsequently, the employee's truck was involved in a road accident with a car, which resulted in death or serious injury to the occupants of the car. The employer settled the claim, and then sued the physician for losses. The employer alleged that the physician's assessment of the employee had been negligent, because the employee had a number of physical impaiments which rendered him unfit to drive.

The "hired gun" perception in the adversarial process indeed results in further polarization. Fortunately, most scientists serve the courts well. Most scientists do not operate in a vacuum, and few practice with unwavering opinions. Some fields of study are rigid enough to permit a definitive (white and black) opinion and an example of such a field of study is statistical analysis. This field of study can and does serve well where white and black exists, as very little grey exists.

Expert witnesses should seek to provide the courts with the essential facts in making a decision; however, there can be techniques used where subtle deletion of very important information misdirects the court from the original issue. Experts who are steered away from their roots may forget the basics. This perspective leaves the public no option but to view with skepticism the role of the expert witness and further adds to the crumbling confidence we have in our scientists, who are no longer able to express an opinion without prejudice.

\section{HISTORICAL REVIEW}

The historical basis behind expert testimony provides us with some appreciation of why we have not yet gone full circle in the evolution of the expert witness. Gee ${ }^{10}$ presents the following interesting review of the historical use of the expert witness. In 1322, it was reported that a group of law students were creating a disturbance in the streets of Tolouse. An official and a guard tried to arrest one of the demonstrators; the mob attacked the official. One of the students struck him in the face, cutting off his nose and part of his lips and chin, and knocking out some teeth. The "expert" surgeon stated that, if he recovered, which he eventually did, he would never again be able to speak intelligibly.

By the 15th century, doctors themselves were becoming involved in the legal process as defendants. In one widely published case in 1424, a man suffered an injury to his thumb and was treated by a barber surgeon. The result of the surgery was not very satisfactory; however, a panel of physicians called to arbitrate considered that a substantial responsibility for this bad outcome lay with the astrological constellations at the time of the incident. 
The First Medical Act of 1511 attempted to control those who practiced medicine and The Royal College of Physicians was granted in a charter of 1518. This established rules of ethics and principles of practice and just how clinicians would perform in public.

In 1678, the first record of adversarial evidence was made when the Earl of Pembroke was charged with the murder of a man. The Earl was known to have a violent temper. Evidence stated that the victim was subject to fits and fainting spells. The primary care physician said he treated him for the injuries and that while drunk, he fell from a chair. This accounted for the death, but not the beating.

An early record of psychiatric evidence appears in 1720 when Lord Ferreas was tried for murder and evidence was given about the state of his mind. The role of the medical expert witness became entrenched when the First Chair in Forensic Medicine was established in Scotland at the end of the 16th century.

The expert witness was previously a volunteer, whereas today, not only are experts well paid, but some professionals have made being an "expert witness" their chosen career path. Historically, the law has been kind to the expert witness, while today's forum puts the expert witness in a different light. The reason for this is in part the phenomenon of the "professional expert" and also because some experts have adopted extreme viewpoints. Experts who practice by "their" rules may forget that they are also subject to all the rules of the adversarial world and the experience itself can become quite unpleasant (especially during cross examination). The fear of failure, the blind conviction to a principle, and even the desire to profit have compromised the role of the expert to an extent whereby the original framework of the expert seemingly no longer exists.

From a historical perspective, we have as experts in some cases evolved to serve ourselves rather than to serve the court. A return of the expert to their original purpose requires that we all reevaluate today's expert. The mediation process does allow experts to move closer to their original purpose, due to the philosophical objective behind mediation.

Scientists will differ in their perspectives and scientific investigations often produce varying results depending on their training and perspective.

Disputes that rely on scientific evidence typically involve three different stakeholders: ${ }^{11}$

1. Individuals or groups who may receive the benefits or bear the costs of a decision.

2. Elected or appointed officials with decision making authority.

3. Technical experts called upon to provide relevant technical expertise. 
In practice, these stakeholders seldom exhibit common goals and their own bias may dominate. Some experts can fold under the pressure applied to them by one of these groups as their objectivity is compromised.

It is usually assumed that scientific experts stand apart from the "political" arena and that scientists work within the protective insulation of their field seeking to establish scientific "facts." On the basis of such "facts," they give informed opinions and the views expressed will be measured against the various policies, plans, roles and regulations; it is assumed that the advice given is sound and apolitical. The following glaring example illustrates that important facts can be unfortunately omitted and change the outcome.

Where legislation is the stakeholder (such as in Workers' Compensation Boards jurisdictions) sufficient confusion in policy wording such as where pre-existing clinical conditions are concerned, can result in obvious weighted decisions as illustrated.

\begin{abstract}
Degenerative arthritis is a normal occurring radiologic finding. Injured workers who have experienced a low back injury will undoubtedly have an $\mathrm{x}$-ray taken of their spine. The clinical examination reveals muscle spasm and loss of range of motion of the back. At the conclusion of the normal period of healing an "independent" medical expert's opinion will be requested. What is noted is that there continues to be disabling pain, with loss of back range of motion. X-rays show degenerative arthritis of the spine. The independent examiner reports this and provides the "case manager" with this information. The case manager interprets the facts and cross correlates this to the written policy. The most important information lacking in the expert opinion is that the literature states there is no correlation between "normal" degenerative arthritis and disabling back pain. The worker, terminated from benefits, appeals the decision. The selective deletion of relevant knowledge has a huge impact on outcome; yet the experts' defence for his opinion is that "I was asked to state what I saw and nothing more." ${ }^{12}$
\end{abstract}

This omission (intentional or not) results in satisfying a policy decision. The impact has both political and economical ramifications; yet the expert opinion is sufficiently anemic to be construed as an expert opinion (with profound political overtones). This very powerful approach reflects poorly on the expert, as truly it is they who should give the whole picture. In a similar vein, the expert who comments on pain being so "intense" that there are no jobs for the patient fails to consider all aspects of disability.

\title{
IV. THE EXPERT AND MEDIATION
}

Knowingly (or unknowingly), the expert witness may feel the adversarial nature of dispute resolution. Public pressure, the expense of controversial decisions and the backlog of trial dates, amongst other pressures, encourage counsel to consider mediation as an option. The example given above undoubtedly evokes a defensive rebuttal. Unfortunately, such a reaction only adds fuel to an issue which is largely grey. Many 
matters could be resolved reasonably quickly and inexpensively through the exchange of information which is encouraged through the mediation process.

Disagreement among scientists is normal and necessary to advance any field of study. Ozawa ${ }^{13}$ has two explanations for the illusion (in the public's eye) that controversy exists. First, the expert's intentional use of certain rhetorical devices may cause confusion; second, the scientists involved may be addressing essentially different questions. This is consistent with the expert opinion being kept in context.

Scientists on both sides frequently resort to phrases they are comfortable with, such as: "there is no evidence to show that analysis is unhelpful, either because data are lacking or the available data are inconclusive"; this confuses the lay audience. That scientists use such language implies that a scientific disagreement existed. Thus, while scientists may actually agree that no conclusive evidence to support either claim is available, their public statements sound like they disagree about the facts. The facts are not in dispute. Different forms of measurement were used to translate the facts into statistical expressions; in doing so, experts influence their audience accordingly. Presenting an opinion in this way is designed to pull public opinion in different directions.

Thomas Khun states that "scientific knowledge" is built on shared beliefs and when there are different conclusions from the same fact pool, the difference in conclusion might be explained by the fact that scientists are trained in different schools of thought. ${ }^{14}$ Different conclusions may not necessarily mean that scientists disagree; rather, it may mean merely that they approach the problem differently. For example, an engineer evaluating highway options may choose the alternative most likely to increase the flow of traffic, while an ecologist or economist will pick their "best" option, which is to minimize traffic flow.

Uncertainty is the major obstacle for scientists, especially those working on the front lines of scientific research and those determined to break new ground. This uncertainty is the very reason that there must be an exchange of information and ideas among experts. The adversarial environment retards this exchange of information and therefore, the search for the truth is more conducive to the mediation environment.

Mediation offers the greatest opportunity for constructive interaction between scientists and the stakeholders. Mediation supports flexibility and provides a forum to exchange concepts without compromising schools of thought. Information sharing is the key to scientific analysis and this sharing of knowledge further advances the quest for scientific truth. Mediation removes the tactic of information suppression and encourages joint factfinding through collaborative efforts.

Models can be used to facilitate a settlement as long as the model structure is perceived as neutral with respect to the interests of the parties involved. 
Mediation may take many forms: ${ }^{15}$

a. Rights-based mediation, where the goal is to settle the dispute as regards the identifiable legal rights of the parties.

b. Interest-based mediation focus on the interests or compelling issues involved in the dispute, rather than focusing on individual rights.

c. The therapeutic approach focuses on the problem-solving skills of the parties involved. The mediator may emphasize the emotional dimensions of the dispute. Often, parties discuss ways of handling similar conflicts in the future.

The limits to mediation include: ${ }^{16}$

a. The readiness to mediate.

b. The parties' willingness to make concessions.

c. One party or the other adopting a position from which they cannot retreat.

d. Instability on the part of either party.

The detailed mediation process is not discussed here, but some comments about the role of the expert in it can be made. To properly involve the expert, one must focus on closing the gap between that which polarizes the two parties. A decision must first be made as to whether the expert's contribution is mechanical, creative or deflective in nature. Where no gap exists with expert testimony, then the joint submission of evidence can be agreed on by each side. This minimizes expenditures and reduces the potential for compromising the expert. In mediation: ${ }^{17}$

1. There must be emphasis placed on the fact that failure to settle can be costly.

2. If the gap is small, the mediator may suggest splitting the difference.

3. Creative options should be explored and discussed.

4. There should be a focus on the needs of the parties, away from rights and positions.

5. Use of the last best offer technique is effective in the early stages - ask for the bottom line.

6. Parties should be encouraged to rephrase offensive messages and stress the positives.

When experts cannot be moved to the middle, the appointment of a neutral expert may help.

The neutral expert concept was used by the Institution of Civil Engineers in their Arbitration Procedure. This procedure is as follows: ${ }^{18}$

E.A. Frank, Alternate Dispute Resolution (American Bar Association Standing Committee on Dispute Resolution, 1989). 
1. A statement of the factual findings sought.

2. A report or statement from and signed by each party-appointed expert upon whom the party relies.

3. Copies of any other documents referred to by each party appointed-expert's report or statement on which the party relies, identifying the origin and date of each document.

The neutral expert then fixes a date when he meets each side's appointed expert whose reports or statements have been submitted. At the meeting, each party-appointed expert can address the mutual expert and put questions to the other expert.... After the hearing the neutral expert may make and publish an award setting out such details or particulars as may be necessary giving his decision upon the issues questioned.

In the true mediation format, the role of the Neutral Expert Fact Finder (NEFF) can be a lonely one. The role of the NEFF is to reevaluate the technical evidence and encourage experts to critically look at their own assessment. There are many reasons why neutral experts are not popular. Our system does not like paying for an additional expert report. Lawyers are cautious about divulging too much information, as the information might go against their case. Experts resent an intruder (the NEFF) and even the judge or mediator may find it difficult to incorporate another neutral entity into the dispute settlement proceedings.

The mandate of a neutral expert is to criticize and weaken the testimony of one or both parties' experts; this "negative" responsibility does little to endear them to anyone. Neutral experts should not press for a change in viewpoint; rather, they should guide the parties' experts towards the middle. They should encourage experts to strive to: ${ }^{19}$
a. use common language;
b. have a firm grasp of what they are talking about and the relevance of it to the issue;
c. look at the whole picture rather than take a narrow view;
d. acknowledge their perspective and that there are other perspectives;
e. avoid the extremes.

The point where the neutral expert comes into the mediation process can vary: ${ }^{20}$ 


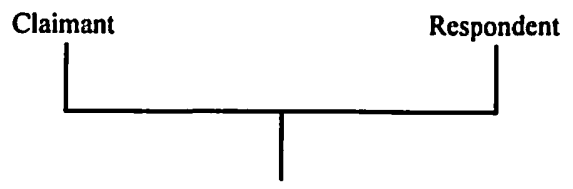

Neutral Expert

Appointed and Agreed

on by Both Sides<smiles>C1CC1</smiles>

Opinion<smiles>[CH]C</smiles>

Mediator

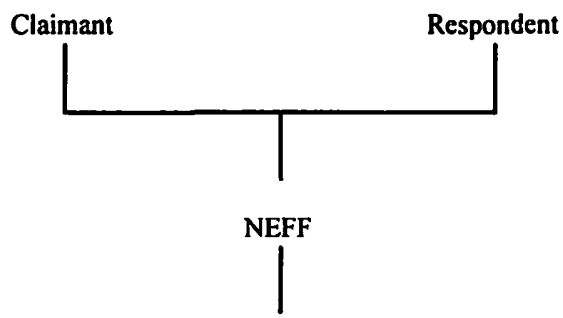

Mediator

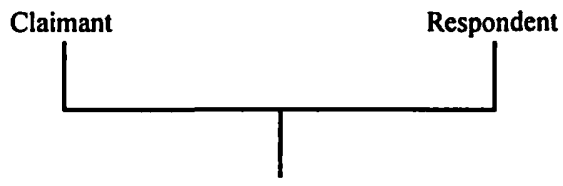

Expert Serves

as the Mediator

As discussed earlier, some fields of study leave few unknowns and with little argument, there is less opportunity for polarization. This article is not intended to answer the question of whether mediation is the best vehicle of dispute resolution. Each forum serves a role, depending on the situation. Where grey dominates and the risk for 
controversial decisions exists, mediation should be strongly considered as the preferred course, given the collaborative efforts of information sharing between experts striving to reach the truth.

Most disputes are resolved before ever going to trial; however, the adversarial process can already be in full swing with many experts being retained. Contrasting opinions lengthen the process and add significant expense. As stated earlier, the contrasting opinions may differ very little and the perception of difference may reflect perspective of viewpoint. There is seldom any exchange of information and knowledge amongst experts; often they function in a vacuum. A double standard sometimes exists, as those victims and counsel whose disbursement pockets are deep can strengthen their position through sheer numbers of experts retained. The courts deserve the best expert that science can offer, not just a "slick professional" who is skilled at public speaking and gives out just enough information to be considered by some to be walking the thin line of ethical compromise.

This article focused on three main topics: advocacy and the expert, a brief description of the historical basis of experts, and mediation and the expert. Focusing on the expert in the adversarial environment seems to be the norm in today's environment of dispute resolution. The negative side of this focus is that we see the expert witness becoming increasingly jaundiced in their opinion. This unnecessary position is difficult to avoid, given the adversarial philosophy of our courts. Further, the intent of this article is to illustrate that the expert practicing in the community may be different than the retained expert witness and that the courts may not be truly benefitting from that which the general community of experts can offer. Mediation can bring experts closer to their "normal practice environment" and with a proper exchange of information, an educated opinion is given, well supported by facts which build upon each other in a natural sense.

Experts can also function in court similar to the way they carry out their practice in the community, as it is in court that some reputations are built. However, this requires encouragement to exchange some information, and a debate on the grey issues. Even though the adversarial environment seldom encourages this exchange, mediation can serve as a therapeutic example in steering the expert back to the very roots of their field, thus bringing them full circle.

\section{PREPARING THE EXPERT}

Differences exist when an expert is prepared for mediation in contrast to serving as an expert witness for plaintiff or defence. There are obvious and less obvious differences when preparing the expert witness for mediation or trial. Initially, the expert may be guided in their report writing and their answering of questions prepared by counsel. In mediation, the questions may be global and the expert may even be asked to put into perspective their opinion as it relates to the larger picture. Shayne ${ }^{21}$ 
recommends that the doctor be informed about the whole case and points out that this advice stems from the natural curiosity of doctors. Experts have this sense of curiosity and wish to know how their evidence fits into the whole scheme of the case. To shelter the expert from the issues surrounding the case may be dangerous and even counterproductive in mediation. Earlier, reference was made to how narrow a perspective experts can function in, yet given the opportunity, experts are able to extrapolate their knowledge and findings to the whole. The expert's interpretations, conclusions, and formulated opinion (as correct or incorrect as it may be) can be debated behind the scenes, rehearsed prior to trial or openly discussed, as in mediation. There is little room for error when being cross-examined. In mediation, while error is not acceptable, the expert should be prepared to discuss flaws in theories and areas of grey, which thus encourages movement rather than positioning.

Shayne recommends that the medical expert therefore discuss unfavourable aspects of "the case," which can be expanded to include weak areas of the case, their report and that of other experts. The trial lawyer can use this information to deflect and direct his position, whereas in mediation, this information serves to bring the two sides closer together. This feature distinguishes mediation from trial and must be kept in perspective when preparing the expert.

Volunteering information during examination-in-chief and during cross-examination can be dangerous if the expert is not clear in his or her own mind about the ramifications and implications of statements made. The lawyer who allows their expert to discuss "their" perception of the issue at large must have confidence and knowledge of where their expert will go. Experts might pontificate if given the chance. The lawyer must have confidence that this freedom of expression will serve a purpose and impress the judge or jury without leaving an opening for cross-examination. On the other hand, latitude is encouraged in mediation where perspectives may not change but movement towards the middle can occur through discussion. In mediation, the expert is prepared and encouraged for a free exchange as the lawyer may want her expert to relay more than just the facts. Open ended questions deserve caution in the courtroom, while in mediation this is encouraged, and may often result in creative solutions only attainable through constructive face-to-face debate amongst experts.

In conclusion, when "grey" dominates and prevails, experts from both sides should be encouraged to exchange thoughts and perspectives. It may be that the responsibility for encouraging this intellectual exchange rests with counsel, occurring prior to appearing before the judge and jury. In mediation, not only can this occur prior to the meeting but an opportunity exists during the dispute resolution process. A neutral expert can bring experts closer together, particularly when experts from different fields, backgrounds and training have differing views on the same issue. The expressed viewpoint of each expert may only be relevant given their perspective and the context in which the opinion is given. Indeed, there is risk to counsel in taking this open approach; the principles behind the adversarial system could be compromised. Efforts encouraging experts to communicate with each other early in a case may shorten the process of issue resolution. In the event that experts are unable to agree, decision by trial still exists. Mediation stands on its own as an appropriate tool for dispute 
resolution. What can also be learned from this process relating to the role and performance of experts can be generalized to other dispute resolution models without compromising the principle behind each approach. 